\title{
Anti-inflammatory effects of a methanolic extract of Castanea seguinii Dode in LPS-induced RAW264.7 macrophage cells
}

\author{
YOURIM LIM $^{1,2}$, JI-WON PARK ${ }^{1}$, OK-KYOUNG KWON ${ }^{1}$, JAE-WON LEE ${ }^{1}$, HAN-SOL LEE $^{1,2}$, SANGWOO LEE $^{3}$, \\ SANGHO CHOI $^{3}$, WANYI LI ${ }^{4}$, HANG JIN ${ }^{4}$, SANG-BAE HAN ${ }^{2}$ And KYUNG-SEOP AHN ${ }^{1}$ \\ ${ }^{1}$ Natural Medicine Research Center, Korea Research Institute of Bioscience and Biotechnology, Cheonju-si, \\ Chungcheongbuk-do 28116; ${ }^{2}$ College of Pharmacy, Chungbuk National University, Cheongju-si, Chungcheongbuk-do 28160; \\ ${ }^{3}$ International Biological Material Research Center, Korea Research Institute of Bioscience and Biotechnology, \\ Daejeon 34141, Republic of Korea; ${ }^{4}$ Institute of Medicinal Plants, Yunnan Academy of \\ Agricultural Sciences, Kunming, Yunnan 650200, P.R. China
}

Received July 6, 2017; Accepted October 24, 2017

DOI: $10.3892 /$ ijmm.2017.3223

\begin{abstract}
Castanea extracts are known to have antioxidant properties and are used as a traditional medicine in China and Asia. However, the biological activity of Castanea seguinii Dode has remained to be fully elucidated. The present study investigated the anti-inflammatory effects of a Castanea seguinii Dode methanolic extract (CSME) on lipopolysaccharide-induced RAW264.7 macrophage cells. CSME inhibited the production of nitric oxide (NO) and the expression of inducible NO synthase. It also suppressed the production of the pro-inflammatory cytokines inteleukin-6 and tumor necrosis factor- $\alpha$, as well as chemokine monocyte chemoattractant protein 1 . In addition, CSME inhibited nuclear factor- $\kappa \mathrm{B}(\mathrm{NF}-\kappa \mathrm{B})$ and mitogen-activated protein kinase (MAPK) signaling, while also downregulating transcription factor activator protein-1. Furthermore, CSME increased heme oxygenase 1 through the upregulation of NF (erythroid-derived 2)-like-2 (Nrf-2), which directly or indirectly affects inflammation. It also increased the phosphorylation of 5'-adenosine monophosphate-activated protein kinase (AMPK). In conclusion, CSME was demonstrated to exert its anti-inflammatory activities through the inhibition of the NF- $\kappa \mathrm{B}$ and the MAPK signaling pathways, as well as the activation of Nrf-2 and AMPK. These results indicated that
\end{abstract}

Correspondence to: Professor Sang-Bae Han, College of Pharmacy, Chungbuk National University, Osongsaengmyeong 1-ro, Osong-eup, Heungdeok-gu, Cheongju-si, Chungcheongbuk-do 28160, Republic of Korea

E-mail:shan@chungbuk.ac.kr

Dr Kyung-Seop Ahn, Natural Medicine Research Center, Korea Research Institute of Bioscience and Biotechnology, 30 Yeongudanji-ro, Ochang-eup, Cheongwon-gu, Cheonju-si, Chungcheongbuk-do 28116, Republic of Korea

E-mail:ksahn@kribb.re.kr

Key words: Castanea seguinii, anti-inflammatory, RAW264.7, lipopolysaccharide, nuclear factor- $\kappa \mathrm{B}$, mitogen-activated protein kinase
CSME may be a promising for development as a commercial anti-inflammatory medicine.

\section{Introduction}

Inflammation is a biological defense mechanism in response to microbes and risk factors such as harmful stimuli and pathogens. The inflammatory response involves inflammatory cells, complement mediators and molecular mediators. In particular, macrophages have an important role in the immediate responses to external stimuli such as lipopolysaccharides (LPS) (1). LPS are extracellular components of Gram-negative bacteria, which cause various inflammatory reactions. Toll-like receptor 4 (TLR4) is a class of proteins expressed on the cell surface to recognize LPS, which leads to signal transmission and macrophage cells activation $(2,3)$. TLR4-mediated signaling activates inflammatory pathways such as the mitogen-activated protein kinase (MAPK) pathways and nuclear factor- $\kappa \mathrm{B}(\mathrm{NF}-\kappa \mathrm{B})$ signaling (4).

The transcription of NF- $\kappa \mathrm{B}$ and activator protein-1 (AP-1) in inflammatory pathways produces inflammatory mediators, cytokines and chemokines (2). Particularly nitric oxide (NO), an inflammatory mediator, has an important role in the pathogenesis of inflammation-associated diseases (5). In LPS-stimulated macrophages, NO is significantly increased, and as part of the early inflammatory response, the secretion of cytokines, including interleukin-6 (IL-6) and tumor necrosis factor- $\alpha(\mathrm{TNF}-\alpha)$, is also increased. The increase of these inflammatory mediators and pro-inflammatory cytokines causes chronic inflammation and may even develop into an inflammatory disease (6).

In addition, previous studies have suggested that NF (erythroid-derived 2)-like-2 (Nrf-2), a protective factor against oxidative stress, is involved in anti-inflammatory processes $(7,8)$. Nrf-2/heme oxygenase-1 (HO-1) signaling has been reported to downregulate the overproduction of inducible NO synthase (iNOS) and pro-inflammatory cytokines (9). The transcription of HO-1 following Nrf-2 activation inactivates or neutralizes NF- $\mathrm{B}$ signaling (10). 5'-Adenosine monophosphate-activated protein kinase (AMPK) has various functions 
and acts as a sensor of stress in the cytoplasm. AMPK has been studied as a target to interfere with inflammatory signaling. The AMPK pathway indirectly inhibits $\mathrm{NF}-\kappa \mathrm{B}$ signaling (11) and the phosphorylation of AMPK has direct or indirect antiinflammatory effects (12).

Castanea seguinii Dode (CS), also known as Castanea davidii Dode or Chinese Chinquapin, is a plant belonging to the Castanea genus of the Fagaceae family. The fruit of various species of the Castanea genus is known to be edible, and the honey of Castanea sativa has antioxidant and antibacterial effects (13), while its fruit has been used for medicinal purposes to treat inflammation (14). Leaves, chestnut burs and the bark of Castanea plants were used for natural medicine products, which are robust and effective in treating nutrition issues, including nutrient deprivation as well as hemostasis, diarrhea, nausea and vomiting. CS is widely used as a traditional remedy in Asia; however, its biological activity and the underlying mechanisms have remained to be fully elucidated. The present study hypothesized that CS methanolic extract (CSME) exerts its anti-inflammatory effects by directly targeting inflammatory signaling, while also targeting molecules indirectly associated with inflammation. These effects were the focus of the present study.

\section{Materials and methods}

Preparation of the plant extract. Leaves and stems of Castanea seguinii (Maoli) were collected from LinAn, (Hangzhou, China) (15) and identified by S.W. Lee. Dried Castanea seguinii leaves and stems (221 g) were ground and extracted with 3 volumes of $\mathrm{MeOH}$ followed by sonication several times for over the course of three days to obtain CSME as a powder (63 g).

Cell culture. RAW264.7 macrophage cells (ATCC, Manassas, VA, USA) were subcultured in Dulbecco's modified Eagle's medium (Gibco; Thermo Fisher Scientific, Inc., Waltham, MA, USA) supplemented with a $1 \%$ antibiotic-antimycotic solution and fetal bovine serum (FBS; Gibco; Thermo Fisher Scientific, Inc.) in a humidified atmosphere containing $5 \% \mathrm{CO}_{2}$ at $37^{\circ} \mathrm{C}$.

Cell viability assay. Cell viability was determined by an MTT assay. RAW264.7 cells at a density of $1 \times 10^{4}$ cells/well were seeded into 96-well plates and stimulated with CSME at various concentrations $(5-40 \mu \mathrm{g} / \mathrm{ml})$ for $24 \mathrm{~h}$. Subsequently, $5 \mu \mathrm{l}$ MTT stock (5 mg/ml; Amresco, LLC, Solon, OH, USA) was added to each well, followed by incubation for $4 \mathrm{~h}$. After removing the supernatant, the formazan crystals that had formed were dissolved by addition of dimethyl sulfoxide and agitation for $10 \mathrm{~min}$ at room temperature. The absorbance at $570 \mathrm{~nm}$ was then measured to determine the optical density that was proportional to the amount of viable cells.

NO assay. RAW264.7 cells were seeded in a 96-well culture plate (SPL, Gyeonggi-do, Korea) at $5 \times 10^{4}$ cells/well were incubated for $16 \mathrm{~h}$, followed by pretreatment with CSME for 30 min and subsequent incubation with LPS (Sigma-Aldrich; Merck KGaA, Darmstadt, Germany) at $0.5 \mu \mathrm{g} / \mathrm{ml}$ for $24 \mathrm{~h}$. NO secretion in the culture supernatant was determined using the Griess reagent (Griess reagent I, 1\% sulfanilamide; Griess reagent $\mathrm{II}, 0.1 \% \mathrm{~N}$-(1-naphathyl)-ethylenediamine dihydro- chloride and 5\% phosphoric acid) and incubated while shaking at room temperature for $10 \mathrm{~min}$. The concentration of NO was measured at $540 \mathrm{~nm}$.

Enzyme-linkedimmunosorbentassay(ELISA).Pro-inflammatory cytokines in the culture supernatant were determined using ELISA kits (TNF set, cat. no. 558534; IL-6 set, cat. no. 555240; BD Biosciences, Santa Clara, CA, USA; and MCP-1 set, cat. no. DY479; R\&D Systems, Inc., Minneapolis, MN, USA) using. The 96-well microplates used in this study were coated with a carbonate-bicarbonate buffer $\left(0.05 \mathrm{M}\right.$; pH 9.6) overnight at $4^{\circ} \mathrm{C}$. The plates were incubated with a blocking buffer (10\% FBS in PBS) at room temperature for $1 \mathrm{~h}$ and then washed. Subsequently, CSME and Dex were pretreated for $1 \mathrm{~h}$ and then treated with LPS. After $24 \mathrm{~h}$, the diluted supernatant and a standard were added to each well, followed by incubation at room temperature for $2 \mathrm{~h}$. The samples were then washed and incubated with a horseradish peroxidase (HRP)-conjugated detection antibody in blocking buffer at room temperature for $1 \mathrm{~h}$. Concentrations were determined with a substrate solution (BD Biosciences) at room temperature for $30 \mathrm{~min}$, at which point the reaction was stopped with $\mathrm{H}_{2} \mathrm{SO}_{4}$ and the absorbance read at $450 \mathrm{~nm}$.

Reverse transcription-polymerase chain reaction analysis $(R T-P C R)$. Total RNA was harvested at $6 \mathrm{~h}$ after a pretreatment with CSME for $1 \mathrm{~h}$ followed by treatment with LPS. The total RNA was isolated using TRIzol ${ }^{\circledR}$ reagent (Invitrogen; Thermo Fisher Scientific, Inc.). The synthesis of complementary DNA was performed using a QuantiTect reverse transcription kit (cat. no. 205310; Qiagen, Hilden, Germany) with $1 \mu \mathrm{g}$ of RNA. For PCR amplification, the primer sequences used were as follows: $\beta$-actin sense, $5^{\prime}$-TGT TTG AGA CCT TCA ACA CC-3' and antisense, 5'-CGC TCA TTG CCG ATA GTG AT-3'; iNOS sense, 5'-CAA GAG TTT GAC CAG AGG ACC-3' and antisense, 5'-TGG AAC CAC TCG TAG TTG GGA-3'. The PCR conditions were as follows: $94^{\circ} \mathrm{C}$ for $5 \mathrm{~min}$ followed by 30 cycles of $94^{\circ} \mathrm{C}$ for $30 \mathrm{sec}, 60^{\circ} \mathrm{C}$ for $30 \mathrm{sec}$, and $72^{\circ} \mathrm{C}$ for $45 \mathrm{sec}$ and a final extension at $72^{\circ} \mathrm{C}$ for 10 min. The GoTaq ${ }^{\circledR}$ G2 Green Master Mix (cat. no. M7823; Promega, Madison, USA) was used. PCR products were separated on a $1.5 \%$ agarose gel with RedSafe ${ }^{\mathrm{TM}}$ kits (Intron Biotechnology, Inc., Gyeonggi-do, Korea). Images of the gels were captured with an Olympus C4000 zoom camera system (Olympus, Tokyo, Japan) and were analyzed by ImageJ software (version 1.50e; National Institutes of Health, Bethesda, MD, USA).

Western blot analysis. The RAW264.7 cells were pretreated with CSME for 1 h. NP40 (cat. no. EBA-1049; Elpis Biotech, Inc., Daejeon, Korea) and NE-PER Nuclear and Cytoplasmic Extraction Reagents (cat. no. 78833; Thermo Fisher Scientific, Inc.) were used for protein extraction. A Pierce ${ }^{\mathrm{TM}} \mathrm{BCA}$ Protein assay kit (cat. no. 23225; Thermo Fisher Scientific, Inc.) was used to quantify the extracted protein. Total protein, cytosolic protein and nuclear protein were separated by $12 \%$ sodium dodecyl sulfate-polyacrylamide gel electrophoresis (SDS-PAGE) $(20 \mu \mathrm{g})$ and the samples were transferred onto polyvinylidene fluoride membranes (EMD Millipore, Billerica, MA, USA). The membranes were blocked with $5 \%$ skimmed milk, followed by incubation with primary 
A

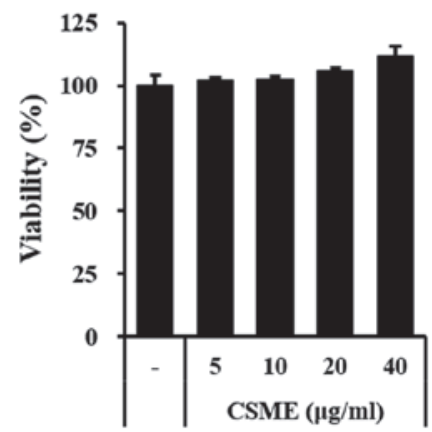

C

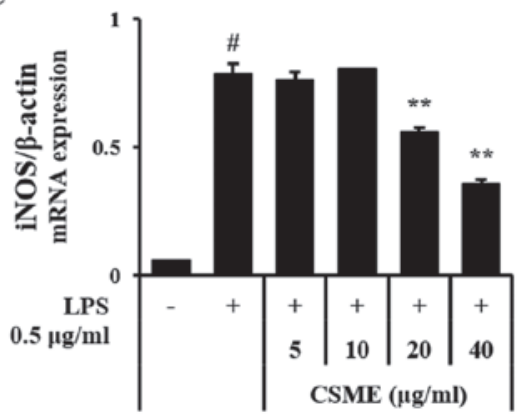

B

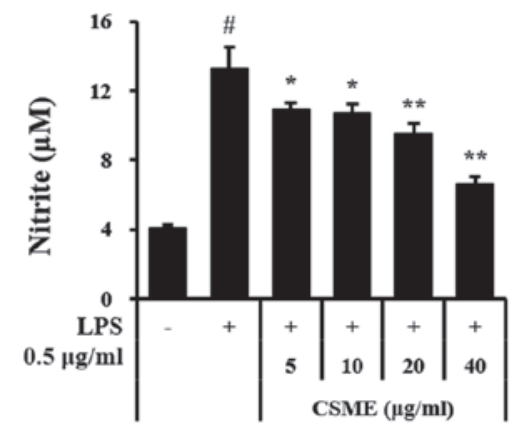

D

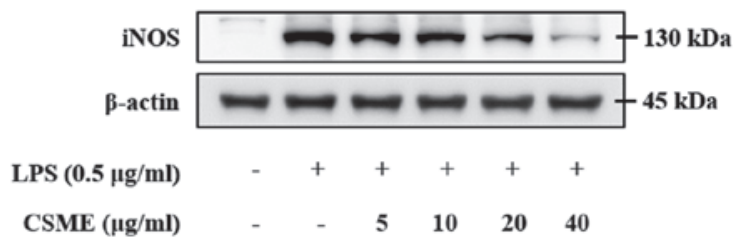

Figure 1. Inhibitory effects of CSME on NO production and iNOS expression levels in LPS-induced RAW264.7 cells. (A) Cytotoxicity of CSME (5-40 $\mu \mathrm{g} / \mathrm{ml}$ ) vs. control detected by an MTT assay. (B) NO production levels in RAW264.7 cells induced with LPS $(0.5 \mu \mathrm{g} / \mathrm{ml})$ with or without pretreatment with CSME was measured using Griess reagents. In addition, iNOS expression was measured by (C) reverse-transcription polymerase chain reaction at the mRNA level and (D) western blot analysis at the protein level. ${ }^{~} \mathrm{P}<0.05$ vs. control; ${ }^{*} \mathrm{P}<0.05$ and ${ }^{* * *} \mathrm{P}<0.01$ vs. cells treated with LPS alone. CSME, Castanea seguinii Dode methanolic extract; LPS, lipopolysaccharide; NO, nitrogen oxide; iNOS, inducible NO synthase; Castanea seguinii Dode methanolic extract.

antibodies overnight at $4^{\circ} \mathrm{C}$. The following primary antibodies and dilutions were used: Anti- $\beta$-actin (cat. no. 4967), anti-phosphorylated (p)-extracellular signal-regulated kinase (ERK; cat. no. 4370), anti-p-p38 (cat. no. 9211), anti-p-AMPK

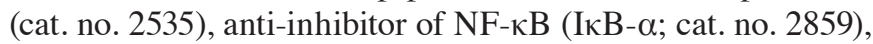
anti-c-Fos (cat. no. 2250), anti-c-Jun (cat. no. 9165) (1:1,000 dilution; Cell Signaling Technology, Inc., Danvers, MA, USA), anti-iNOS (cat. no. ADI-905-431, 1:1,000 dilution; Enzo Life Science, Farmingdale, NY, USA), anti-p-c-Jun N-terminal kinase (JNK) (cat. no. sc-6254), anti-JNK (cat. no. sc-474), anti-ERK (cat. no. sc-154), anti-p38 (cat. no. sc-7149), anti-Nrf-2 (cat. no. sc-722), anti-AMPK (cat. no. sc-25792) and anti-proliferating cell nuclear antigen (PCNA; cat. no. sc-56, 1:1,000 dilution; Santa Cruz Biotechnology, Inc., Dallas, TX, USA). The membranes with the primary antibodies were washed three times with Tris-buffered saline containing $0.1 \%$ Tween-20 (TBS-T) for $10 \mathrm{~min}$. Finally, the membranes were incubated with HRP-conjugated secondary antibodies (anti-mouse, cat. no. sc-2005; anti-rabbit, cat. no. sc-2030; 1:5,000 dilution; Santa Cruz Biotechnology, Inc.) at room temperature for $1 \mathrm{~h}$. The membranes were washed three times with TBS-T for $10 \mathrm{~min}$ and an enhanced chemiluminescence kit (cat. no. 32106; Thermo Fisher Scientific, Inc.) was used to visualize the protein bands (LAS-4000 luminescent image analyzer; Fujifilm, Tokyo, Japan). For quantification, band density values were assessed using Fuji Multi Gauge version 3.0 (Fujifilm).

Immunohistochemistry assay. RAW264.7 cells were seeded into Chamber Slides (Thermo Fisher Scientific, Inc.) incubated overnight and then washed. Subsequently, they were fixed with $4 \%$ paraformaldehyde and treated with $0.1 \%$ Triton X-100 (Bio-Rad Laboratories, Inc.) to permeabilize the membrane. Subsequently, samples were incubated overnight at $4^{\circ} \mathrm{C}$ with the first antibody to Nrf-2 (cat. no. sc-722, 1:200 dilution; Santa Cruz Biotechnology, Inc.). Subsequently, slides were treated with Alexa Fluor 488-conjugated secondary antibody (cat. no. A-11034; Thermo Fisher Scientific, Inc.) for $1 \mathrm{~h}$ at room temperature for nuclear staining, Hoechst 33342 was added, followed by washing and mounting with Vectashield ${ }^{\circledR}$ medium (Vector Laboratories, Inc., Burlingame, CA, USA). The cells were observed and images were captured with an LSM 510 Meta system (Carl Zeiss AG, Oberkochen, Germany).

Statistical analysis. Values are expressed as the mean \pm standard error of the mean. Statistical significance was determined by analysis of two-group for Student's t-test (Excel 2013; Microsoft Corp., Redmond, WA, USA). P $<0.05$ was considered to indicate a statistically significant difference.

\section{Results}

Inhibitory effect of CSME on LPS-induced NO production. To assess the effect of CSME on cell viability, RAW264.7 cells were treated with CSME for $24 \mathrm{~h}$ and subjected to the MTT assay. The results indicated cell viability exceeded $95 \%$ of CSME at a concentration of 5-40 $\mu \mathrm{g} / \mathrm{ml}$ (Fig. 1A). Based on this outcome, an NO assay was performed in order to determine the inhibitory effects of CSME on inflammation. The LPS-induced production of NO in RAW264.7 cells was clearly 
A

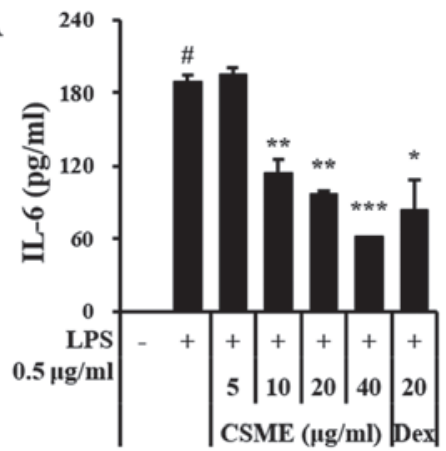

B

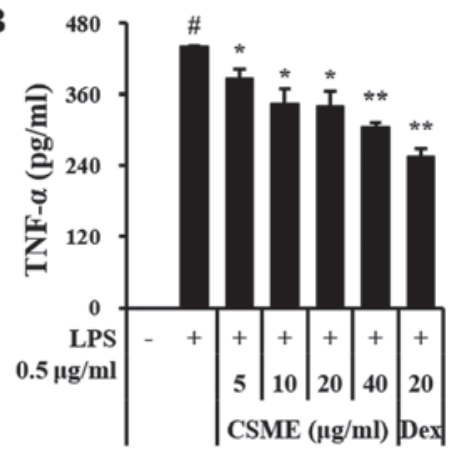

C

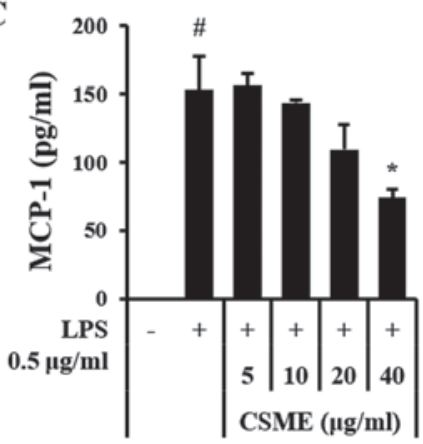

Figure 2. Effects of CSME on pro-inflammatory cytokines in LPS-induced RAW264.7 cells. Cells were pretreated with CSME (5-40 $\mu \mathrm{g} / \mathrm{ml})$ for $1 \mathrm{~h}$, followed by a treatment with LPS $(0.5 \mu \mathrm{g} / \mathrm{ml})$ for $24 \mathrm{~h}$ and measurement of (A) IL-6, (B) TNF- $\alpha$ and (C) MCP-1 by ELISA. ${ }^{*} \mathrm{P}<0.05$ vs. control; ${ }^{*} \mathrm{P}<0.05,{ }^{* *} \mathrm{P}<0.01$ and ${ }_{* * * *} \mathrm{P}<0.001$ vs. cells treated with LPS alone. LPS, lipopolysaccharide; CSME, Castanea seguinii Dode methanolic extract; IL-6, interleukin-6; TNF- $\alpha$, tumor necrosis factor- $\alpha$; MCP-1, monocyte chemoattractant protein-1; Dex, dexamethasone; ELISA, enzyme-linked immunosorbent assay.

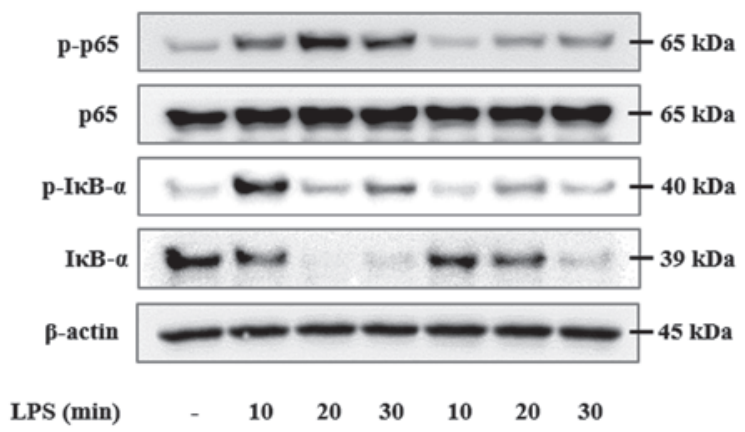

$\operatorname{CSME}(40 \mu \mathrm{g} / \mathrm{ml})$

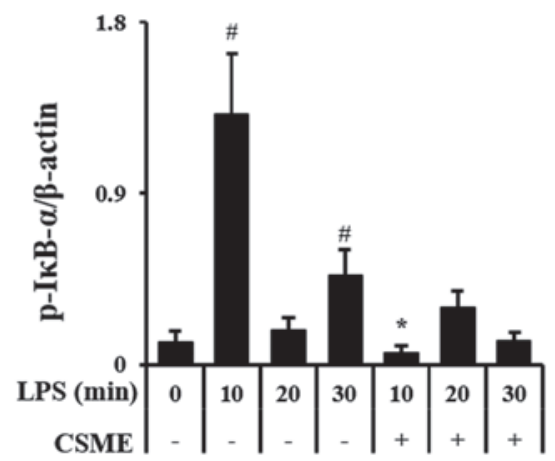

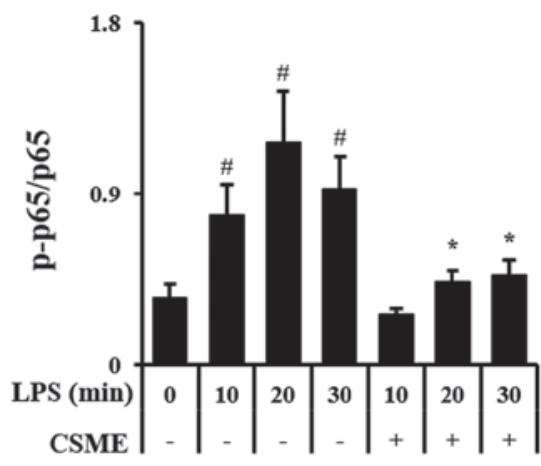

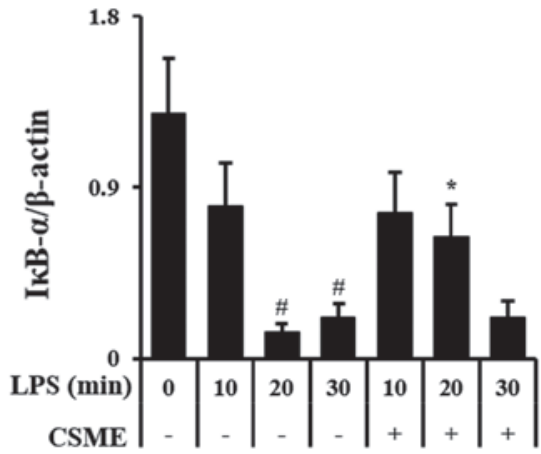

Figure 3. Inhibitory effect of CSME on NF-kB signaling in LPS-induced RAW264.7 cells. Cells were pretreated with or without CSME (5-40 $\mu \mathrm{g} / \mathrm{ml})$ for $1 \mathrm{~h}$ and then treated with LPS $(0.5 \mu \mathrm{g} / \mathrm{ml})$ for 10,20 or $30 \mathrm{~min}$, after which the phosphorylation of IкB- $\alpha$, p65 and the degradation of IкB- $\alpha$ were detected by western blot analysis. Western blot bands were densitometrically quantified using ImageJ software. ${ }^{"} \mathrm{P}<0.05$ vs. control; ${ }^{*} \mathrm{P}<0.05$ vs. cells treated with LPS alone. CSME, Castanea seguinii

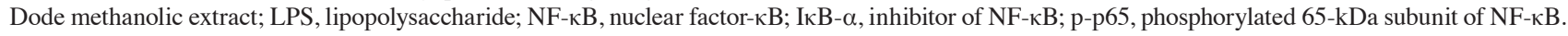

decreased by pretreatment with CSME (Fig. 1B). The effects of CSME on the mRNA and protein levels of iNOS were also assessed. In agreement with the above results, the LPS-induced expression of iNOS was inhibited by pretreatment with CSME in a dose-dependent manner (Fig. 1C and D).

Inhibitory effects of CSME on LPS-induced pro-inflammatory cytokine and chemokine secretion. ELISAs were performed to determine whether CSME affected the expression levels of pro-inflammatory cytokines and chemokines. The results demonstrated that the increased expression of IL- 6 and TNF- $\alpha$ in LPS-treated RAW264.7 cells was inhibited by pretreatment with CSME (Fig. 2A and B) and that the secretion of monocyte chemoattractant protein-1 (MCP-1) was also markedly decreased (Fig. 2C).

Effects of CSME on LPS-induced upregulation of NF- $\kappa B$ and $M A P K$ signaling. In order to elucidate the molecular mechanisms of action of CSME, RAW264.7 cells were treated with LPS for 10, 20 and $30 \mathrm{~min}$ with or without pretreatment by CSME, and the phosphorylation outcomes of p65 and IкB- $\alpha$ along with the degradation of IкB- $\alpha$ were assessed by western blot analysis. The rapid increase of $\mathrm{p}-\mathrm{I} \mathrm{KB}-\alpha$ after stimulation with LPS was inhibited by pretreatment with CSME, and the degradation of IкB- $\alpha$ was also decreased. LPS-induced phosphorylation of p65 was also decreased by CSME (Fig. 3). 
A

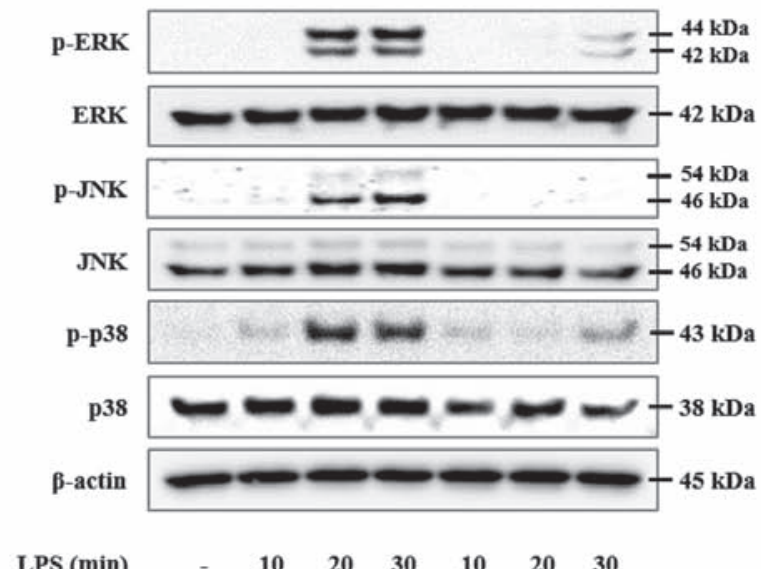

B

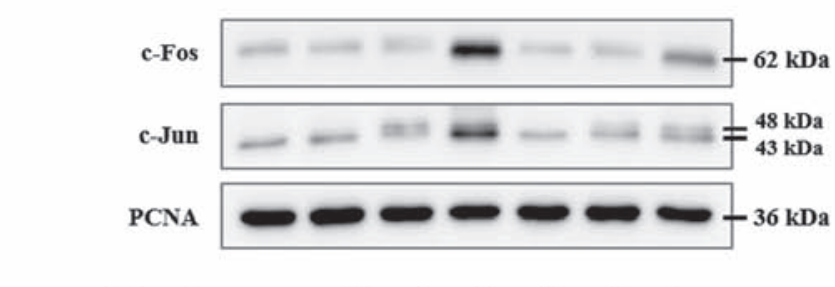

$\begin{array}{llllllll}\text { LPS (min) } & - & 10 & 30 & 60 & 10 & 30 & 60\end{array}$

CSME $(40 \mu \mathrm{g} / \mathrm{ml})$

CSME (40 $\mu \mathrm{g} / \mathrm{ml})$

Figure 4. Downregulation of activator protein-1 transcription factor components through inhibition of mitogen-activated protein kinases by CSME in LPS-induced RAW264.7 cells. (A) Cells were pretreated with or without CSME (5-40 $\mu \mathrm{g} / \mathrm{ml})$ for $1 \mathrm{~h}$ and then treated with LPS (0.5 $\mu \mathrm{g} / \mathrm{ml})$ for 10,20 or $30 \mathrm{~min}$, after which the phosphorylation of JNK, ERK and p38 were compared by western blot analysis. (B) Furthermore, the nuclear protein fraction was isolated, in which c-Fos and c-Jun were subsequently detected by western blot analysis. CSME, Castanea seguinii Dode methanolic extract; LPS, lipopolysaccharide; p-ERK, phosphorylated extracellular signal-regulated kinase; JNK, c-Jun N-terminal kinase; PCNA, proliferating cell nuclear antigen.

The present study also investigated the effects of CSME on MAPK signaling proteins in order to determine which molecular signaling pathways of inflammation it interferes with. RAW264.7 cells were pretreated with or without CSME and then stimulated with LPS for 10, 20 or $30 \mathrm{~min}$, followed by assessment of the phosphorylation of the MAPKs by western blot analysis. The results demonstrated that the phosphorylation levels of ERK, JNK and p38 were increased in the LPS-treated RAW264.7 cells (the phosphorylation of JNK and ERK peaked at $30 \mathrm{~min}$, while that of $\mathrm{p} 38$ peaked at $20 \mathrm{~min}$ ). However, these LPS-induced increases of p-JNK, p-ERK and p-p38 in RAW264.7 cells were significantly inhibited by pretreatment with CSME (Fig. 4A). In the same manner, involvement of the AP-1 signaling pathway was confirmed. Nuclear translocation of c-Fos and c-Jun was increased in RAW264.7 cells after treatment with LPS for 10, 30 and $60 \mathrm{~min}$ in a time-dependent manner. Of note, the translocation of c-Fos and c-Jun was significantly reduced in the cells pretreated with CSME (Fig. 4B).

Effect of CSME on Nrf-2 and AMPK. Nuclear protein was isolated and Nrf-2, a transcription factor associated with anti-oxidative processes, was assessed by western blot analysis (Fig. 5). Nuclear Nrf-2 was increased by CSME in a dose-dependent manner (Fig. 5A). CSME also increased translocation of Nrf-2 in LPS-induced RAW264.7 cells (Fig. 5B). In order to confirm the translocation of Nrf-2 into the nucleus, an immunohistochemistry assay was performed. The results demonstrated that the translocation of Nrf-2 in RAW264.7 cells was increased by CSME with or without LPS (Fig. 5E and F). In addition, the production of HO-1 was increased by CSME in a dose-dependent manner in RAW264.7 cells with or without LPS treatment (Fig. 5C and D).

Subsequently, the effect of CSME on the phosphorylation of AMPK in RAW264.7 cells was examined. CSME-treated RAW264.7 cells were harvested at intervals of $30 \mathrm{~min}, 1 \mathrm{~h}$ and $2 \mathrm{~h}$. The phosphorylation of AMPK exceeded the basal level at
1 and $2 \mathrm{~h}$ of CSME treatment (Fig. 6A). In addition, RAW264.7 cells were pretreated with CSME and then stimulated with LPS for $2 \mathrm{~h}$, after which the levels of p-AMPK were assessed by western blot analysis. In the cells treated with LPS alone, the levels of p-AMPK were decreased; however, this effect was inhibited by CSME (Fig. 6B). CSME increased p-AMPK in the presence and in the absence of LPS in RAW264.7 cells.

\section{Discussion}

Macrophages have an important role in inflammation. Their induction with stimulants such as LPS leads to macrophage activation by a variety of inflammatory signaling mechanisms, leading to the secretion of inflammatory mediators and cytokines $(1,16)$. In particular, TLR signaling by external stimuli is essential for innate immune responses, and it results in the activation of inflammatory transcription factors such as NF-кB and AP-1 (17). Thus, in the present study, the anti-inflammatory effects of pretreatment with CSME on LPS-induced inflammatory response in the RAW264.7 mouse macrophage cell line were observed.

$\mathrm{NF}-\mathrm{\kappa B}$, consisting of the $\mathrm{p} 65$ and $\mathrm{p} 50$ subunits, is a transcription factor that induces the expression of inflammatory genes. These subunits block IкB- $\alpha$ in its normal state, but upon stimulation by the inflammatory response, I $\mathrm{B}-\alpha$ undergoes phosphorylation and is degraded, while NF- $\mathrm{kB}$ is activated (18). LPS induces the activation of NF- $\mathrm{BB}$, which then stimulates the expression of pro-inflammatory cytokines, including IL-6 and TNF- $\alpha$, as well as chemokines (19). Therefore, the present study confirmed that CSME suppressed LPS-induced inflammatory mediators and cytokines, as well as phosphorylation of IкB- $\alpha$ and p65, in RAW264.7 cells. Therefore, it was demonstrated that CSME has anti-inflammatory effects through inhibition of NF- $\mathrm{KB}$ signaling.

MAPKs are a class of protein kinases that have the function of directing cellular responses to external stimuli. MAPK signaling refers to the activation of ERK, JNK and p38 $(20,21)$. 
A

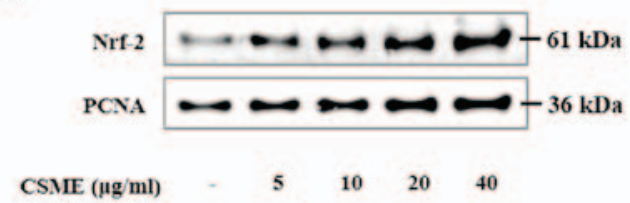

C

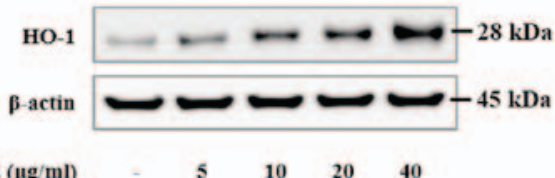

$\begin{array}{lllll}\text { CSME }(\mu \mathrm{g} \mathrm{ml}) & 5 & 10 & 20 & 40\end{array}$
B

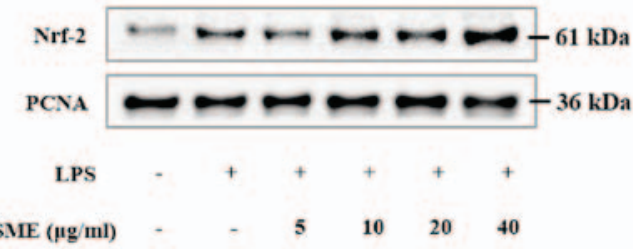

D

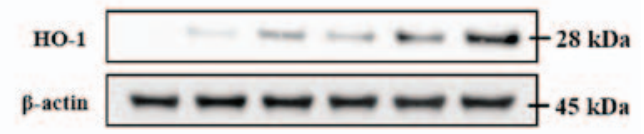

LPS

CSME $(\mu \mathrm{g} / \mathrm{ml}) \quad-\quad-\quad \begin{array}{lllll}5 & 10 & 20 & 40\end{array}$

F

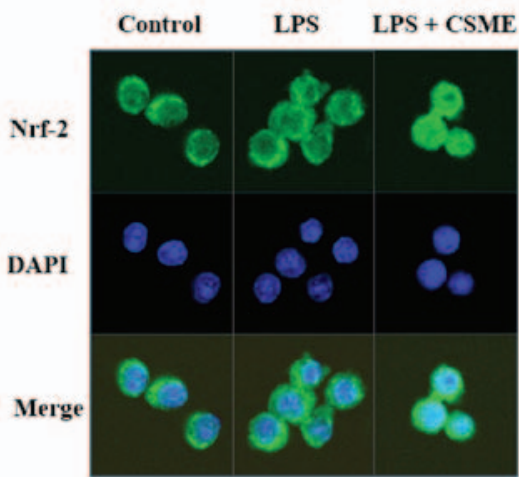

Figure 5. The effects of CSME included an increase of the production of HO-1 through the upregulation of Nrf-2. (A) After pretreatment with CSME $(5-40 \mu \mathrm{g} / \mathrm{ml})$, the nuclear (lower panel) and cytosolic (lower panel) protein fractions were isolated and the expression of Nrf-2 was measured by western blot analysis. (B) After pretreatment with CSME, LPS treated RAW264.7 cells were isolated and the expression of Nrf-2 was measured. (C) The expression of HO-1 was measured in RAW264.7 cells treated with CSME (5-40 $\mu \mathrm{g} / \mathrm{ml})$. (D) CSME was treated with LPS together to confirm the expression of HO-1. (E and F) The nuclear translocation of Nrf-2 was measured by immunohistochemistry. Cells were observed under a confocal microscope and images were captured with LSM 510 Meta software. Magnification, x400. CSME, Castanea seguinii Dode methanolic extract; LPS, lipopolysaccharide; HO-1, heme oxygenase 1; Nrf-2, nuclear factor (erythroid-derived 2)-like-2; PCNA, proliferating cell nuclear antigen.

$\mathbf{A}$

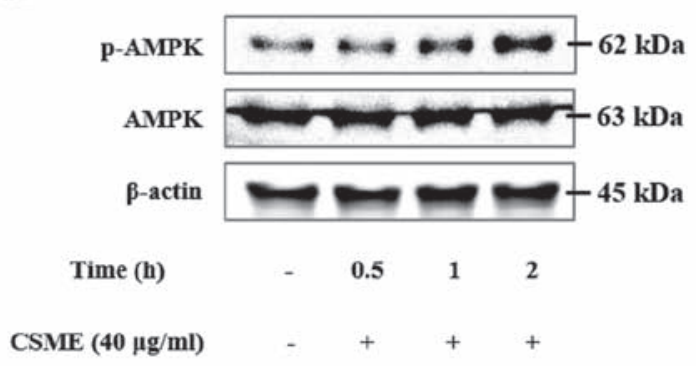

B

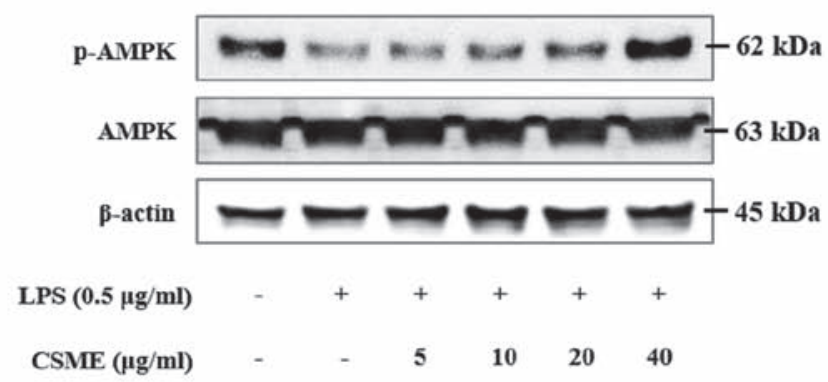

Figure 6. CSME activates AMPK in RAW264.7 cells. (A) After treatment of RAW264.7 cells with CSME (5-40 $\mu \mathrm{g} / \mathrm{ml})$ for $30 \mathrm{~min}, 1 \mathrm{and} 2 \mathrm{~h}$, the phosphorylation of AMPK was measured by western blot analysis. (B) The increased levels of p-AMPK in RAW264.7 cells were measured after treatment with CSME in induction with LPS $(0.5 \mu \mathrm{g} / \mathrm{ml})$. CSME, Castanea seguinii Dode methanolic extract; LPS, lipopolysaccharide; p-AMPK, phosphorylated adenosine monophosphate kinase.

MAPKs also regulate the activity of the AP-1 transcription factor. AP-1 is a heterodimer formed by the c-Fos and c-Jun subunits. These are phosphorylated by ERK, JNK and p38 and then translocate to the nucleus $(22,23)$. AP-1 regulates the expression of inflammatory cytokines and inflammatory mediators (6). Accordingly, the present study assessed the effects of the CSME on MAPK signaling. It was revealed that CSME inhibited the LPS-induced phosphorylation of ERK,
JNK and p38 in RAW264.7 cells. In addition, the effect on the downstream AP-1 was assessed, which demonstrated that CSME inhibited the LPS-induced nuclear translocation of c-Fos and c-Jun in RAW264.7 cells. Taken together, CSME was indicated to inhibit the activation of AP-1 by suppressing the activation of MAPK signaling. These results indicated that CSME appears to block the upstream kinases of NF- $\kappa \mathrm{B}$ and MAPKs (Fig. 7). 


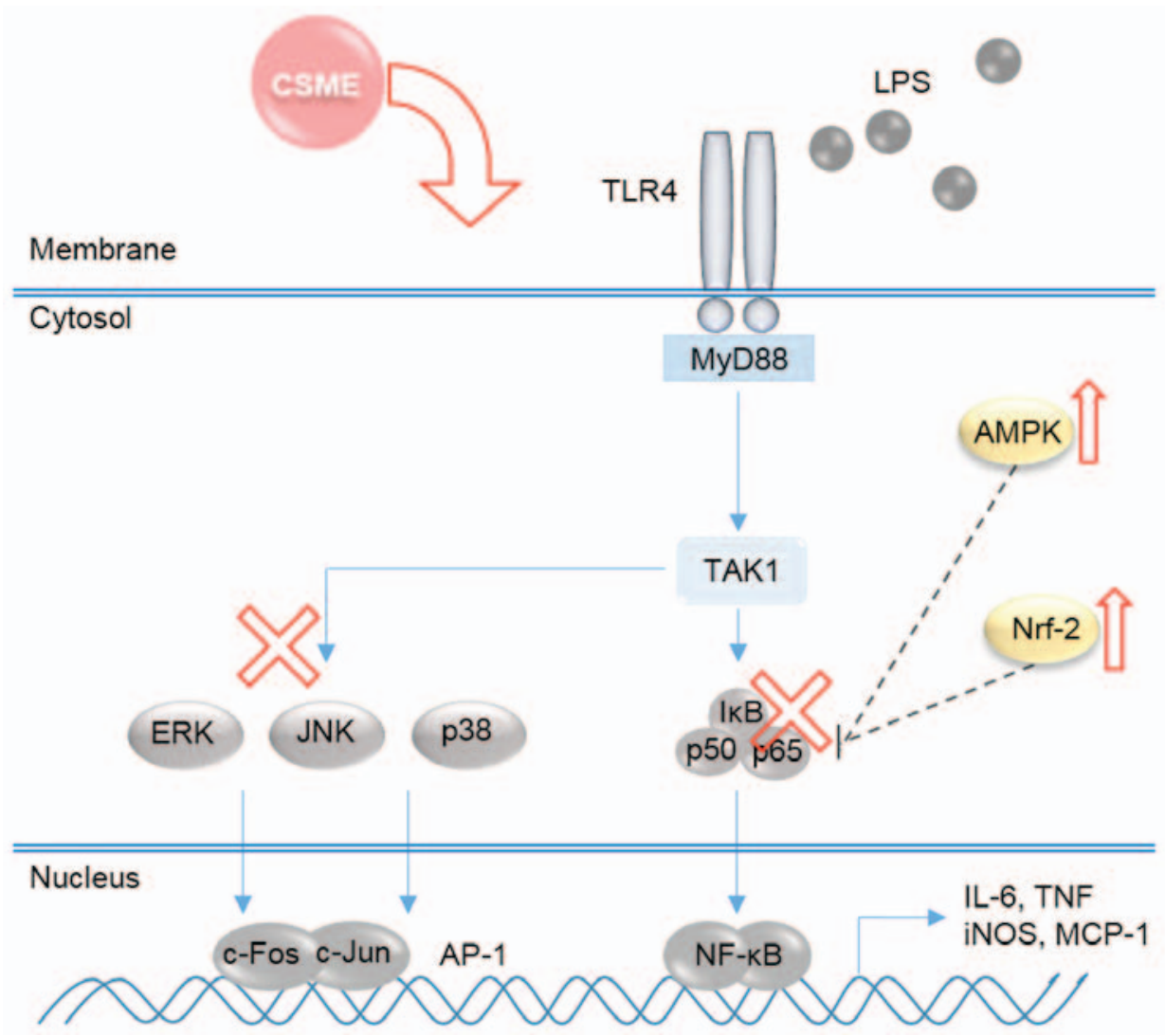

Figure 7. Schematic diagram illustrating the mechanisms underlying the anti-inflammatory effects of CSME. CSME, Castanea seguinii Dode methanolic

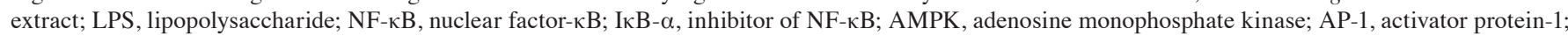
Nrf-2, nuclear factor (erythroid-derived 2)-like-2; iNOS, inducible nitrogen oxide synthase; ERK, extracellular signal-regulated kinase; JNK, c-Jun N-terminal kinase; IL-6, interleukin-6; TNF- $\alpha$, tumor necrosis factor- $\alpha$; MCP-1, monocyte chemoattractant protein-1; TLR, Toll-like receptor; MyD88, myeloid differentiation primary response gene 88 ; TAK1, transforming growth factor $\beta$-activated kinase 1 .

HO-1, an enzyme that catalyzes the degradation of heme, is expressed following activation of $\mathrm{Nrf}-2$ through oxidative stress (24). Increased production of HO-1 was demonstrated to decrease the inflammatory response in an endotoxin shock model (25). The present study confirmed that CSME increases HO-1 by activating Nrf-2. CSME also increased the translocation of Nrf-2 into the nucleus in RAW264.7 cells. The production of HO-1 in RAW264.7 cells was also increased by CSME. These results demonstrated that CSME has an antioxidant effect. High concentrations of LPS induce a large amount of oxidative stress and Nrf-2 is activated as a defense mechanism. As a result, CSME activates Nrf-2 and increases the expression of HO-1 without being affected by LPS in RAW264.7 cells (Fig. 5).

AMPK was reported to be involved in the inflammatory response. AMPK deficiency increased the expression of LPS-induced pro-inflammatory cytokines in macrophages (26). The activation of AMPK has been demonstrated to downregulate $\mathrm{NF}-\mathrm{\kappa B}$, and AMPK therefore also functions as an anti-inflammatory agent (27). In addition, AMPK/activating transcription factor 3 signaling inhibits the phosphorylation of $\mathrm{p} 38$, which led to a protective effect of AMPK activation in an LPS-induced murine endotoxemia model (28). In macrophages, the AMPK/Sirtuin 1 pathway was reported to exert anti-inflammatory effects through deacetylation of NF- $\kappa B$ (29). Activation of Nrf-2 was reported to have AMPK-dependent anti-inflammatory effects, and the functional association between AMPK and the Nrf-2 pathway has an important role in the suppression of inflammation (12). The present study observed the effects of CSME on AMPK, which is involved in anti-inflammatory responses. CSME had the effect of activating AMPK reduced by LPS stimulation in RAW264.7 cells. The results of the present study indicated that CSME has anti-inflammatory effects via various molecular targets by directly or indirectly acting on TLR4 signaling stimulated by LPS (Fig. 7). Thus, the present study confirmed that AMPK and Nrf-2 are involved in anti-inflammatory responses.

In conclusion, the present study demonstrated that CSME suppressed the LPS-induced production of inflammatory mediators and inflammatory cytokines in RAW264.7 macrophage cells by inhibiting the NF- $\kappa \mathrm{B}$ and MAPK signaling pathways, while also enhancing the anti-inflammatory activity through the activation of Nrf-2 and AMPK. It is therefore suggested that CSME has therapeutic potential in inflammation-associated diseases.

\section{Acknowledgements}

This study was supported by the National Foundation for Science and Technology Development (grant no. NRF-2016K1A1A8A01939075) and the KRIBB of Korea (grant no. KGM1221713). Some aspects of the present study were reported as posters at the 8th KRIBB Poster Festival (2016; Daejeon, Korea). 


\section{References}

1. Gordon S: Alternative activation of macrophages. Nat Rev Immunol 3: 23-35, 2003.

2. Beutler B: Inferences, questions and possibilities in Toll-like receptor signalling. Nature 430: 257-263, 2004.

3. Yamamoto M, Sato S, Hemmi H, Uematsu S, Hoshino K, Kaisho T, Takeuchi O, Takeda $\mathrm{K}$ and Akira S: TRAM is specifically involved in the Toll-like receptor 4-mediated MyD88independent signaling pathway. Nat Immunol 4: 1144-1150, 2003.

4. Hong JM, Kwon OK, Shin IS, Jeon CM, Shin NR, Lee J, Park SH, Bach TT, Hai V, Oh SR, et al: Anti-inflammatory effects of methanol extract of Canarium lyi C.D. Dai \& Yakovlev in RAW 264.7 macrophages and a murine model of lipopolysaccharideinduced lung injury. Int J Mol Med 35: 1403-1410, 2015.

5. Islam T, Breton C, Salam MT, McConnell R, Wenten M, Gauderman WJ, Conti D, Van Den Berg D, Peters JM and Gilliland FD: Role of inducible nitric oxide synthase in asthma risk and lung function growth during adolescence. Thorax 65 : $139-145,2010$

6. Lu Y, Suh SJ, Kwak CH, Kwon KM, Seo CS, Li Y, Jin Y, Li X, Hwang SL, Kwon O, et al: Saucerneol F, a new lignan, inhibits iNOS expression via MAPKs, NF- $\kappa$ B and AP-1 inactivation in LPS-induced RAW264.7 cells. Int Immunopharmacol 12 175-181, 2012.

7. Kim J, Cha YN and Surh YJ: A protective role of nuclear factorerythroid 2-related factor-2 (Nrf2) in inflammatory disorders. Mutat Res 690: 12-23, 2010.

8. Kobayashi EH, Suzuki T, Funayama R, Nagashima T, Hayashi M, Sekine H, Tanaka N, Moriguchi T, Motohashi H, Nakayama K, et al: Nrf2 suppresses macrophage inflammatory response by blocking proinflammatory cytokine transcription. Nat Commun 7: $11624,2016$.

9. Cai ZY, Sheng ZX and Yao H: Pachymic acid ameliorates sepsis-induced acute kidney injury by suppressing inflammation and activating the Nrf2/HO-1 pathway in rats. Eur Rev Med Pharmacol Sci 21: 1924-1931, 2017.

10. Lee SH, Sohn DH, Jin XY, Kim SW, Choi SC and Seo GS: 2',4',6'-tris(methoxymethoxy) chalcone protects against trinitrobenzene sulfonic acid-induced colitis and blocks tumor necrosis factor-alpha-induced intestinal epithelial inflammation via heme oxygenase 1-dependent and independent pathways. Biochem Pharmacol 74: 870-880, 2007.

11. Salminen A, Hyttinen JM and Kaarniranta K: AMP-activated protein kinase inhibits NF- $\kappa \mathrm{B}$ signaling and inflammation: Impact on healthspan and lifespan. J Mol Med (Berl) 89: 667-676, 2011.

12. Mo C, Wang L, Zhang J, Numazawa S, Tang H, Tang X, Han X, Li J, Yang M, Wang Z, et al: The crosstalk between Nrf2 and AMPK signal pathways is important for the anti-inflammatory effect of berberine in LPS-stimulated macrophages and endotoxinshocked mice. Antioxid Redox Signal 20: 574-588, 2014

13. Kolayli S, Can Z, Yildiz O, Sahin H and Karaoglu SA: A comparative study of the antihyaluronidase, antiurease, antioxidant, antimicrobial and physicochemical properties of different unifloral degrees of chestnut (Castanea sativa Mill.) honeys. J Enzyme Inhib Med Chem 31 (Suppl 3): 96-104, 2016.
14. Zlatanov MD, Antova GA, Angelova-Romova MJ and Teneva OT: Lipid composition of Castanea sativa Mill. and Aesculus hippocastanum fruit oils. J Sci Food Agric 93: 661-666, 2013.

15. Ahn K: The worldwide trend of using botanical drugs and strategies for developing global drugs. BMB Rep 50: 111-116, 2017.

16. Chen IT, Hsu PH, Hsu WC, Chen NJ and Tseng PH: Polyubiquitination of transforming growth factor $\beta$-activated Kinase 1 (TAK1) at lysine 562 residue regulates TLR4-mediated JNK and p38 MAPK activation. Sci Rep 5: 12300, 2015.

17. Kueanjinda P, Roytrakul S and Palaga T: A novel role of numb as a regulator of pro-inflammatory cytokine production in macrophages in response to Toll-like receptor 4. Sci Rep 5: 12784, 2015.

18. Ajibade AA, Wang HY and Wang RF: Cell type-specific function of TAK1 in innate immune signaling. Trends Immunol 34: 307-316, 2013.

19. Park JW, Kwon OK, Yuniato P, Marwoto B, Lee J, Oh SR, Kim JH and Ahn KS: Amelioration of an LPS-induced inflammatory response using a methanolic extract of Lagerstroemia ovalifolia to suppress the activation of NF- $\kappa$ B in RAW264.7 macrophages. Int J Mol Med 38: 482-490, 2016.

20. Arthur JS and Ley SC: Mitogen-activated protein kinases in innate immunity. Nat Rev Immunol 13: 679-692, 2013.

21. Chang L and Karin M: Mammalian MAP kinase signalling cascades. Nature 410: 37-40, 2001

22. Nateri AS, Spencer-Dene B and Behrens A: Interaction of phosphorylated c-Jun with TCF4 regulates intestinal cancer development. Nature 437: 281-285, 2005

23. Whitmarsh AJ and Davis RJ: Transcription factor AP-1 regulation by mitogen-activated protein kinase signal transduction pathways. J Mol Med (Berl) 74: 589-607, 1996.

24. Guo RF and Ward PA: Role of oxidants in lung injury during sepsis. Antioxid Redox Signal 9: 1991-2002, 2007.

25. Tamion F, Richard V, Renet S and Thuillez C: Intestinal preconditioning prevents inflammatory response by modulating heme oxygenase-1 expression in endotoxic shock model. Am J Physiol Gastrointest Liver Physiol 293: G1308-G1314, 2007.

26. Sag D, Carling D, Stout RD and Suttles J: Adenosine 5'-monophosphate-activated protein kinase promotes macrophage polarization to an anti-inflammatory functional phenotype. J Immunol 181: 8633-8641, 2008.

27. Salminen A and Kaarniranta K: AMP-activated protein kinase (AMPK) controls the aging process via an integrated signaling network. Ageing Res Rev 11: 230-241, 2012.

28. Liu X, Wang N, Fan S, Zheng X, Yang Y, Zhu Y, Lu Y, Chen Q, Zhou $\mathrm{H}$ and Zheng J: The citrus flavonoid naringenin confers protection in a murine endotoxaemia model through AMPKATF3-dependent negative regulation of the TLR4 signalling pathway. Sci Rep 6: 39735, 2016.

29. Xue B, Yang Z, Wang X and Shi H: Omega-3 polyunsaturated fatty acids antagonize macrophage inflammation via activation of AMPK/SIRT1 pathway. PLoS One 7: e45990, 2012. 